\title{
Opinion
}

\section{Sustainable Rural Economic model of India - an emerging economy model for the world in the post covid-19 pandemic era}

\author{
Durgesh Gaur $^{1 *}$ \\ ${ }^{1}$ Propritor, Gayatri Financial Services, Shivpuri, Madhya Pradesh, India \\ *Corresponding email: durgeshgaur26@gmail.com \\ https://doi.org/10.36018/dsiij.v16i.168
}

\begin{abstract}
The COVID19 pandemic impact made a major revision in development thinking that is presenting fundamental challenge to the conventional consensus on economic development. The Indian rural economy is the great economic philosophy which involves economic and social values in itself. The basic model of such economy has several features which makes it self-dependent, the same model had motivated the Indian freedom revolution towards the swadeshi, indigenousness, with the icon of charkha, unified the whole country against foreign economic dominance and later to the freedom. Rural economy serves as the backbone and basic line of evolution of economy. It represents the single working unit with all the functions of economy. In post COVID19 era, need of self-reliance and sustainable economy, could be addressed through rural economical model existed in India since centuries.
\end{abstract}

Keywords. Rural economical model, COVID19, pandemic, sustainable, self-reliance, environment

\begin{abstract}
*The author is a senior equity analyst in 'Sadaram Fund Partners' located in Mumbai, India. He is an editorial columnist on economic views for various newspapers; besides a writer in 'Quora', having more than 2,50,000 viewers. He had worked for 4 years as an assistant professor in the field of finance and economy at Devi Ahalya Vishwavidyalaya, Indoor, Madhya Pradesh, India.
\end{abstract}

The soul of India lies in village. Soul means something eternal, immortal and in simple words sustainable. Something which is sustainable only can become self-reliant (Atmanirbhar). In the days of freedom revolution of India Mahatma Gandhi has visited the whole India to understand it's hidden values, ethics and strength and he found a selfreliant and sustainable economic model in Indian village, which retains the capacity of its sustainability and also solved such passel that how an economic and cultural revolution can beat the economic and political control Britain over the India.

A successful economy needs proper distribution of wealth, which creates employments and makes the people more prosperous. This economic approach bridges the gap between rich and poor, and gives the opportunity of equality. In the modern economic age, we have concentrated our economic growth to a specific industrial areas; no doubt such approach has generated economic output and economic wealth, however it has also caused unequal and unbalanced growth, which had created various inequalities like growing difference between rich and poor, imbalances within the country like rich States and poor States, and also various well known environmental imbalances and hazards (1-2).

For example, in India, because of such modern economic growth the major chunk of working 
population has shifted towards the industrial estates like Maharashtra, Gujarat, Tamilnadu, Andra Pradesh, Delhi and Karnataka from Utter Pradesh, Bihar, Madhya Pradesh and Chhatishgarh, Udisa, Rajisthan and other northern zones of our country. Resultantly, we have been apparently watching hyper inflation in land prices, huge cost of living, highly populated cities, pollution and low quality of life in industrial states. On another hand, backwards states are coping up with regular migration, economic dependence, unemployment, crimes, deficit infrastructure and scarcity of water and electricity, which also reduced their standards and quality of life. Lots of discrepancies are seen in our country which is result of current system with an output-growth-oriented economic model (1-2).

Weaknesses of such model became more visible in the age of corona (COVID19 pandemic) (3). The unrest within the migrant labors to turn back to their home land had been seen as a national phenomenon. If such model had remained capable to sustain its trajectory in fair direction i.e. balance between rural and urban employment, we would have not seen the irony of such withdrawal. To rebalance such situation we should try to rehabilitate our economy in its natural shape which is local economy (4).

The best way to shape the local economy is the restoration of rural economic model (4) because it has the natural sustainable capacity. Still in the villages we can find the economic locality like potter, black smith, gold smith, farmer, labor, milkman, tailor, weaver, local shopkeepers all are doing their jobs locally and are creating and distributing the wealth between each other without the fear of inflation. If our economy involves the new advancement in such rural economic behavior, and let it function in its own culture, definitely we will be able to sort out the various economic and social challenges such as like over populated cities, high living and social costs, health, education, pollution, deficit infrastructure, gap between rich and poor people.

\section{Rural economic model of India}

In India, it is easy to re-start or the re-installation of this model, which Mahatma Gandhi endorsed; more than 50\% population still resides in rural India, which is a great advantage having basic infrastructure. Also it is the need of current time, and Indian government is also promoting it as 'local vocal' and through incorporating through education system.

Manufacturing of products which can be made handmade or at local level (semi-manual) without factory should be made in village. Only items which cannot be made by hand, should be manufactured in industry, thus giving chance to thrive both rural and urban economy and bringing balance between them. Goods made with handmade or semi-manual methods can be supplied to the nearby cities, and thus help reducing pollution and transportation associated carbon foot print. This was happening in India until the modern industrial revolution has happened. This model can also help generate employment and enough resources to survive for all (5-7).

The small village can serve surrounding areas around cities. This is in very minimal form existing in India in the form of micro-industry for following products - cow based products, agriculture bio fertilizer, handmade cloth and handmade utensil, handmade food products like Jam, Jelly, Achar, etc, candles, dhoopsticks, soap. However, there is immense scope of handmade products like toothpaste, biscuits, soap, detergent, boxes, ink, utensils, etc (5).

The ancient Indian educational system of Gurukul was aimed at holistic development which made them great warriors and kings and a better citizen and included basic entrepreneurial skills along with cultural and spiritual teaching in life. Vedic culture provided sustainable economical development through rural lives of India considering need of both 
nature (5) and humans (6), which becomes particular of importance during this COVID19 era.

\section{Reference}

1. Vinayakam K. Rural To Urban Migration in an Indian Metropolis: Case Study Chennai City. IOSR-JHSS [Internet]. 2012;6(3):32-5. Available from: http://dx.doi.org/10.9790/0837-0633235

2. Special Focus: Inequality in Emerging Economies (EEs). OECD. 2011. Available from: https://www.oecd.org/els/soc/49170475.pdf

3. Peterson ozili and ThankonArun. (2020), Spillover of COVID-19: impact on the Global Economy. SSRN Electronic Journal. DOI: 10.2139/ssrn.3562570

4. The Economic Times. Covid-19 presents an opportunity to craft a new economic model, bridge rural-urban divide. Available from: https://economictimes.indiatimes.com/smallbiz/startups/newsbuzz/covid-19-presents-anopportunity-to-craft-a-new-economic-model-bridgerural-urbandivide/articleshow/75370232.cms?utm_source=contento finterest\&utm_medium=text\&utm_campaign=cppst (Accessed on 20th June 2020)

5. Pandya P., Aa raha hain aarthik Samta Ka Yug (The era of financial equality Is coming). Akhand Jyoti Magazine. 2011;72(11):32. Available from http://literature.awgp.org/akhandjyoti/2011/September/v 1.30

6. Pandya P., Arthik Tantra and Paryavaran Ko Vikas Hetu Milkar Chalana Hoga (Economy and Environment has to walk to gather). Akhand Jyoti Magazine. 2004;64(11):29. Available from http://literature.awgp.org/akhandjyoti/2004/September/v 1.29

7. Pandya P., Swavlamban Shiksha Ki Anivarya Sharat Bane (Skill-entrepreneurship shall become integral part of education). Akhand Jyoti Magazine. 1998;58(6):10. Available from http://literature.awgp.org/akhandjyoti/1998/June/v1.10 